\title{
Disposition of ${ }^{14} \mathrm{C}$-labelled Endotelon in humans
}

\author{
A. BENAKIS ${ }^{1}$, C. SCHOPFER' ${ }^{1}$ and J. RITSCHARD ${ }^{2}$ \\ ${ }^{1}$ Laboratory of Drug Metabolism, Department of Pharmacology, Geneva University, Switzerland \\ ${ }^{2}$ Nuclear Medicine Division, Geneva University Hospital, Geneva, Switzerland
}

Received for publication: September 9, 2007

Key words: Endotelon, urinary elimination, faecal elimination, humans

\section{SUMMARY}

In order to study the disposition of ENDOTELON in humans, this compound was labelled with ${ }^{14} \mathrm{C}$ by photosynthesis. ENDOTELON consists of a complex of procyanidolic oligomers extracted from the seeds of a variety of vine cultivated in the Bordeaux wine-growing region, and is prescribed for the treatment of chronic venous insufficiency and retinal lesions.

Considering the difficulty in labelling the various constituents of the product, the labelling procedure was based on providing radioactive $\mathrm{CO}_{2}$ to the plant. After isolation and purification, $150 \mathrm{mg}$ of active material $(50 \mu \mathrm{Cl})$ was administered orally to six healthy volunteers. Radioactivity was measured in the blood over time until 72 and 120 hours in the same subjects after drug administration. Urinary and faecal elimination was measured for a period of 167 hours. Urinary elimination of the radioactive compounds represented 12 to $27 \%$ of the administered dose and faecal elimination represented 47 to $75 \%$ depending on the subject. The radioactivity of the ${ }^{14} \mathrm{CO}_{2}$ eliminated in the breath was also measured, and represented around $8 \%$ of the total radioactivity for the 72-hour period after administration.

Although the disposition of ENDOTELON is based on the total radioactivity measured over time, this technique allows the evaluation of the elimination rate of the product and its metabolites from the human body.

\section{INTRODUCTION}

ENDOTELON $^{\circledR}$ is a product that is prescribed for the treatment of chronic venous insufficiency and retinal lesions (1).

At cell level, ENDOTELON ${ }^{\circledR}$ becomes fixed at mucopolysaccharide level by interfering with the biosynthesis of collagen fibres. This accounts for the reinforcing and protective effect on the vascular coat of the microcirculation of the venous system (2).

From a pharmacological point of view, the therapeutic effect of ENDOTELON ${ }^{\circledR}$ on capillary fragility and on venous tonus results in:

- an increase in capillary resistance, as demonstrated by double-controlled studies including a placebo and a reference substance,

Please send reprint requests to: Professor Dr A. Benakis, Centre Médical Universitaire, 9 Avenue de Champel, 1211 Geneva 4, Switzerland
- a reduction in capillary permeability, as evidenced by various tests (histamine, Landis tests, isotopic method),

- an increase in venous tonus as determined by gas plethysmography in cases of venous occlusion (3),

The active constituents of ENDOTELON consist of a group of procyanidolic oligomers extracted from the seeds of a variety (UNIBLANC) of vine that is essentially cultivated in the Bordeaux (France) wine-growing region (Figure 1).

In order to investigate the disposition of this compound, this study was carried out using a ${ }^{14} \mathrm{C}$-labelled compound, and adopting the appropriate techniques for radioactive measurement $(4,5)$.

In this study ${ }^{14} \mathrm{C}$-labelled ENDOTELON was synthesized by photosynthesis and a pharmaceutical form containing the labelled material was prepared and administered to six healthy human volunteers. 


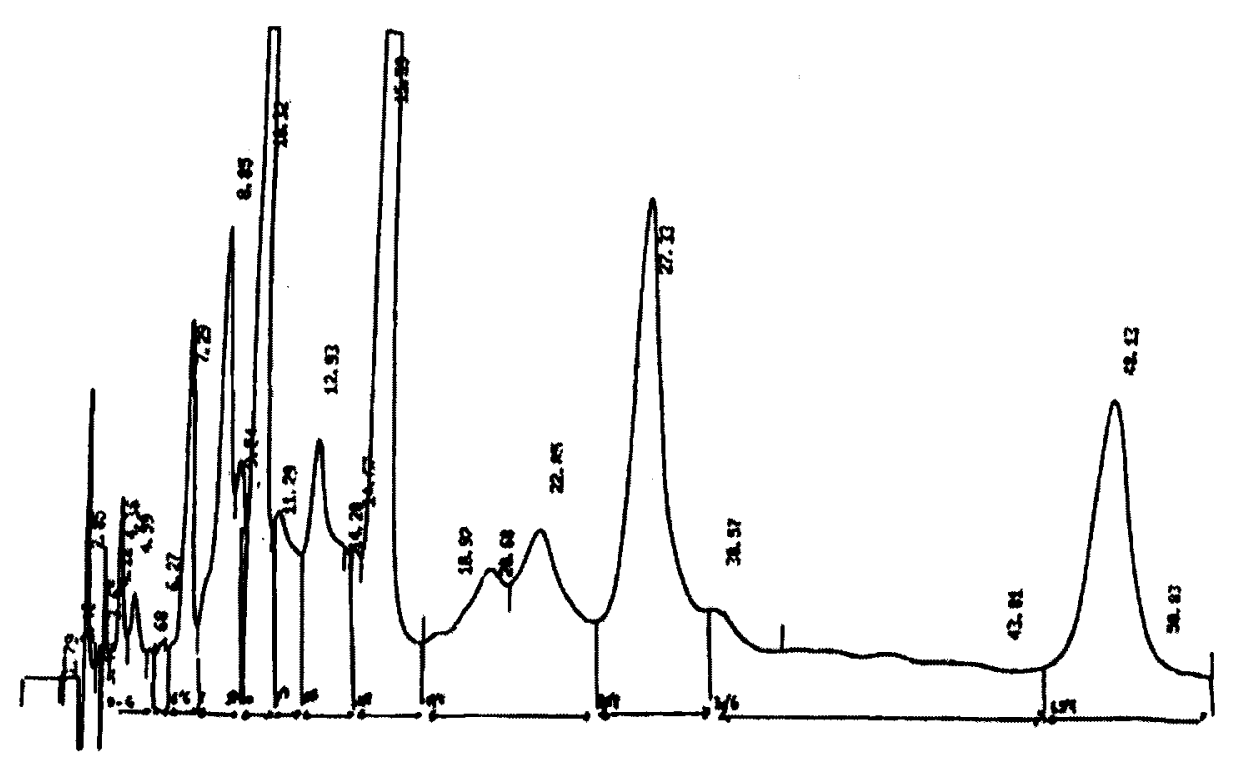

Figure 1. HPLC separation of procyanidolic oligomers

In this paper the specifications of the labelled compound as well as the procedure of the labelled synthesis was described.

A plant of the UNIBLANC strain was enclosed in a $300 \mathrm{~L}$ airtight polyethylene chamber. $\mathrm{A}{ }^{14} \mathrm{CO}_{2}$ atmosphere was obtained in a generator from $\mathrm{Ba}$ ${ }^{14} \mathrm{CO}_{2}(56.6 \mathrm{mCi} / \mathrm{mM})$ and $60 \% \mathrm{H}_{3} \mathrm{PO}_{4}$. The duration of the procedure was 8 days. The grapes were picked about 6 weeks after the labelling procedure, refrigerated in liquid nitrogen and stored at $-30^{\circ} \mathrm{C}$ until processing. The procyanidolic oligomers, which constitute the active principle of ENDOTELON, were extracted from the seeds using a mixture of acetone/water (20/80). After different steps in the procedure (acetone elimination, $\mathrm{NaCl}$ saturation, ethyl acetate extraction) the compound was obtained by precipitation in chloroform.

Different specific activity lots were obtained and, in order to respect the therapeutic dose of the compound and bearing in mind the level of $\mu \mathrm{Ci}$ that the Medical Commission of the University Hospital has authorized, ENDOTELON was prepared with a specific activity of 9.694 and $12.321 \mathrm{KBq} / \mathrm{mg}(6,7)$.

\section{MATERIAL AND METHODS}

\section{Administered pharmaceutical form}

ENDOTELON in the form of a slightly light brown tinted powder was administered without excipient, directly introduced into a capsule (No 0) at a dose of $150 \mathrm{mg}$ with a total activity of around 50 $\mu \mathrm{Ci}$ per capsule $(1.85 \mathrm{MBq})$ to the first three volunteers, and with a total activity of around $40 \mu \mathrm{Ci}$ $(1.48 \mathrm{MBq})$ to the other three volunteers.

\section{Experimental protocol}

The experiment was conducted in six healthy volunteers: four females and two males who had been fully informed of the nature of the experiment and of the study protocol. Preliminary authorization was obtained from the Medical Ethics Committee of the University Hospital where this study was carried out. A detailed study project, namely regarding dosimetry, was submitted to the Ethics Committee in this respect. The data regarding the volunteers - age, body weight, height and body mass - have been given in Table I.

Prior to entry into the study, haematological and biochemical analyses and clinical examinations were performed.

Before oral administration of the product, the subjects fasted. Two hours after administration of the drug, they received a light breakfast. Thereafter they were able to eat normally. However, they had to abstain from ingesting beverages containing alcohol, caffeine and other alkaloids.

Blood samples $(5 \mathrm{ml}$ blood on $0.5 \mathrm{ml}$ of a $3.8 \%$ monosodic citrate solution) were drawn via a permanent butterfly type catheter inserted into a superficial forearm vein of each volunteer. 
Table I. Characteristics of volunteers

\begin{tabular}{|c|c|c|c|c|c|c|}
\hline No & Subject & Year & Sex & Weight $(\mathrm{kg})$ & Height $(\mathrm{cm})$ & Body surface $\left(\mathrm{m}^{2}\right)$ \\
\hline 1 & A:R.B. & 64 & Female & $50 \mathrm{~kg}$ & $168 \mathrm{~cm}$ & $1.56 \mathrm{~m}^{2}$ \\
2 & B:P.R. & 27 & Male & $64 \mathrm{~kg}$ & $174 \mathrm{~cm}$ & $1.77 \mathrm{~m}^{2}$ \\
3 & C:C.W. & 33 & Female & $48 \mathrm{~kg}$ & $154 \mathrm{~cm}$ & $1.43 \mathrm{~m}^{2}$ \\
4 & D:M.M. & 34 & Female & $47 \mathrm{~kg}$ & $163 \mathrm{~cm}$ & $1.48 \mathrm{~m}^{2}$ \\
5 & E:J.M. & 40 & Male & $65 \mathrm{~kg}$ & $170 \mathrm{~cm}$ & $1.75 \mathrm{~m}^{2}$ \\
6 & F:M.S. & 39 & Female & $53 \mathrm{~kg}$ & $163 \mathrm{~cm}$ & $1.56 \mathrm{~m}^{2}$ \\
\hline
\end{tabular}

The blood samples were collected at 30 minutes, 1 hour, 1.30, 2, 3, 4, 5, 6, 8, 10, 24, 48 and 72 hours and for volunteers D, E and F at 120 and 144 hours after drug administration.

Plasma was obtained by centrifugation $(8,000 \mathrm{~g})$ of the blood.

Radioactivity at plasmatic level was measured in 0.5 ml samples using an appropriate scintillation cocktail containing a large volume of water. Absolute values for radioactivity were obtained after correction using the external standard method.

All urines eliminated by each volunteer during the experimental period - over a $167 \mathrm{~h}$ period for volunteer $\mathrm{A}$ and $70 \mathrm{~h}$ for the others were collected according to the natural rhythm of elimination. Each miction was collected separately. The volume of elimination was recorded and the radioactivity measured by liquid scintillation according to a previously described techniques (5). After correction, the values of the urinary elimination of the product and its metabolites were expressed in \% of the eliminated dose of urine over the period in question.

The faeces were collected in an appropriate receptacle for each defaecation according to the natural rhythm of excretion over a period of 7 days after administration of the drug.

The weights of fresh and desiccated faeces were determined and the radioactivity was measured in dry $100 \mathrm{mg}$ samples by a combustion technique (8). After correction, the values of faecal elimination were expressed in $\%$ determined compared to the quantity of drug administered.

Presumably the procedure used for labelling resulted in the introduction of ${ }^{14} \mathrm{C}$ in more than one chemical position of the molecules in question and the metabolic pathway of this compound produced radioactive $\mathrm{CO}_{2}$ that was eliminated in the breath.

\section{Radioactivity measurement at pulmonary level}

The radioactivity of ${ }^{14} \mathrm{CO}_{2}$ eliminated in breath was measured by liquid scintillation technique. $\mathrm{CO}_{2}$ was quantitatively absorbed by a mixture of phenylethanolamine hydroxide of hyamine in methanol over a predetermined time period and at spaced out intervals. The values were expressed as \% of the eliminated dose using a linear elimination rate.

\section{RESULTS}

\section{Haematological and biochemical data}

Haematological and biochemical data for the six subjects show that the values determined for all the volunteers were within the normal physiological limits.

\section{Plasma levels}

The levels of ENDOTELON and its labelled metabolites as a function of time were determined by the measurement of plasma radioactivity, and expressed in terms of nanogram equivalents of the administered product and based on its specific activity. The values were expressed as means and standard deviation (means $\pm S D$ ) and have been given in Figure 2.

From these results, interindividual differences at calculated standard deviation level can be seen. Nevertheless the drawn curve shows that the maximum value was measured around 14 hours after drug administration and that the decrease was relatively low, as after 144 hours, at which time the results for the last three subjects (i.e. D,E,F) were recorded, the values were almost similar to those measured at two and three hours.

\section{Urinary elimination}

The urinary elimination of ${ }^{14} \mathrm{C}$ ENDOTELON and its labelled metabolites were measured as a function of time in six subjects.

The values of urinary elimination were expressed as \% of the administered dose for the first hour and 
for the periods of $0-24,24-48,48-72$ hours for subjects A, B and for the other subjects, i.e. C, D, E, $F$ for the period of 72-96 and 96-120 hours (not appeared in Figure 3). For the subject $A$, the elimination rate was measured up to 168 hours after drug administration.

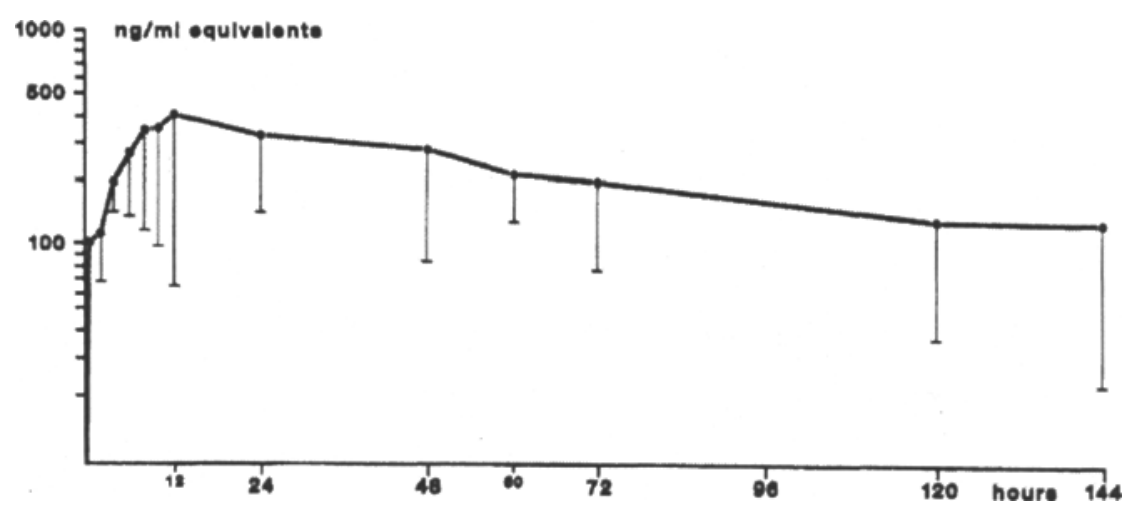

Figure 2. Plasma levels as a function of time (average values and standard deviation in 6 subjects) after oral administration of a $150 \mathrm{mg}$ dose of ${ }^{14} \mathrm{C}$-ENDOTELON. Values on a semi-logarithmic scale are expressed in ng equivalent of unchanged product per ml of plasma

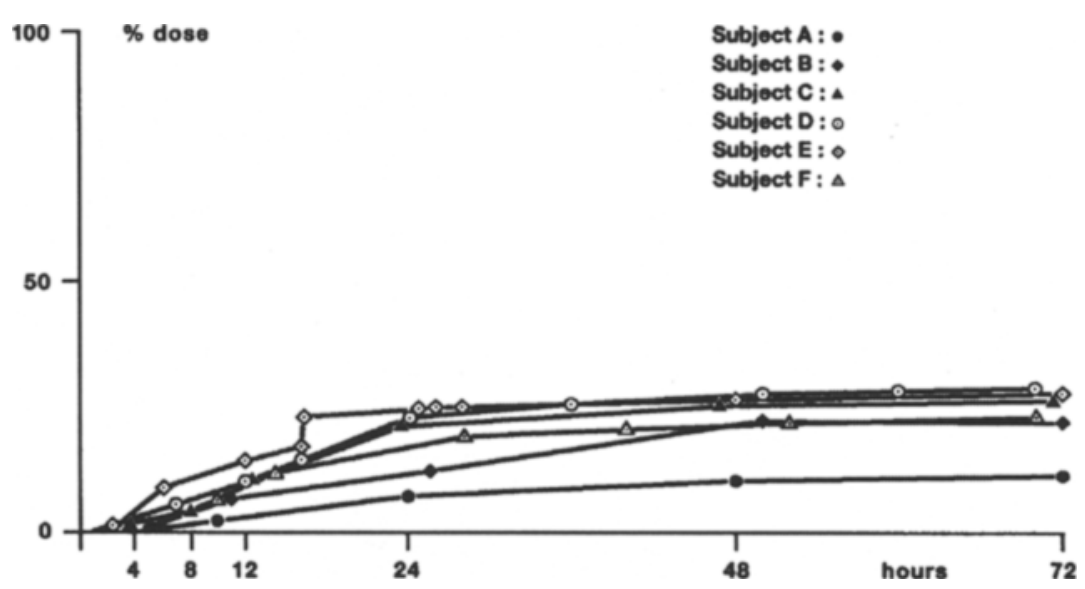

Figure 3. Cumulated urinary elimination as a function of time of ${ }^{14} \mathrm{C}$-ENDOTELON and its labelled metabolites after oral administration of a $150-\mathrm{mg}$ dose to 6 healthy volunteers. Cumulated values are expressed as \% of the administered dose

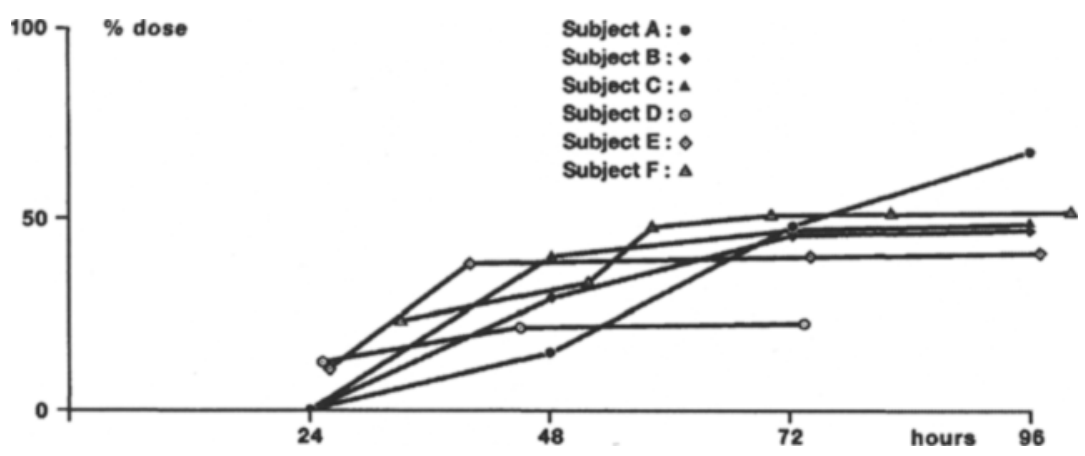

Figure 4. Cumulated faecal elimination as a function of time of ${ }^{14} \mathrm{C}$-ENDOTELON and its labelled metabolites after oral administration of a $150-\mathrm{mg}$ dose to 6 healthy volunteers. Cumulated values are expressed as \% of the administered dose 
Despite interindividual variations, the elimination were coherent compared with the mean values of the elimination in each subject. The urinary elimination rate was around 12 and $27 \%$ of the administered dose.

The urinary elimination as a cumulated value and as a function of time for each subject has been shown in Figure 3.

\section{Faecal elimination}

The faecal elimination of ${ }^{14} \mathrm{C}$-ENDOTELON and its labelled metabolites were measured as a function of time in all six study subjects.

The values of the elimination rate were expressed as $\%$ of the administered dose for the time intervals during the first 24 hours and for the periods from $0-24,24-48,48-72,72-96,96-120$ and 120-144 hours for three subjects, i.e. A, C, F and 144-168 hours (7 days) for three other subjects, i.e. B, D, E after drug administration. These values have been shown for each subject in Figure 4.

Although interindividual variations as regards the \% eliminated by this route were observed, we can consider that the results represented average of faecal elimination.

\section{Pulmonary elimination}

Considering the nature of the labelling by ${ }^{14} \mathrm{C}$ which is general for all carbons of the compound, it is important to evaluate the degree of degradation of the compound structure through the formation of ${ }^{14} \mathrm{CO}_{2}>2$ which is eliminated via the breath. This rate was evaluated during two-hour periods - for the first 12 hours and for longer periods thereafter. The time periods as well as the elimination rate were expressed as $\%$ of the administered dose, whereas the cumulative values for the period of 24 hours and up to 72 hours were recorded, and have been given in Table II.

From these results it can be seen that the elimination rates via this route were relatively similar for all six subjects, and that the most important part was eliminated during the first 24 hours after drug administration.

The breath elimination rate amounted to around $8 \%$ of the administered dose. This value indicates the metabolic degradation of the ENDOTELONlabelled compounds.

Table II. ${ }^{14} \mathrm{CO}_{2}$ elimination by pulmonary route in man for a perind of 72 hours after oral administration of ${ }^{14} \mathrm{C}$ ENDOTELON. Values are expressed as \% of he administered dose

\begin{tabular}{|c|c|c|c|c|c|c|c|}
\hline Time after drug administration $(\mathrm{h})$ & \multicolumn{7}{|c|}{ Study subjects } \\
\hline & A & B & C & D & E & F & M $\pm 2 \sigma$ \\
\hline $0-24$ & 4.67 & 8.58 & 5.45 & 6.77 & 9.07 & 5.41 & $15.62 \pm 5.55$ \\
$24-48$ & - & - & - & - & - & - & - \\
$48-72$ & 1.58 & 0.343 & 1.71 & 0.43 & 3.15 & 1.54 & $6.09 \pm 3.97$ \\
& & 0.072 & 0.52 & & 0.89 & 0.50 & $0.31 \pm 0.19$ \\
\hline Total & 6.25 & 8.99 & 7.68 & 7.20 & 13.11 & 7.45 & $6.44 \pm 2.38$ \\
\hline
\end{tabular}

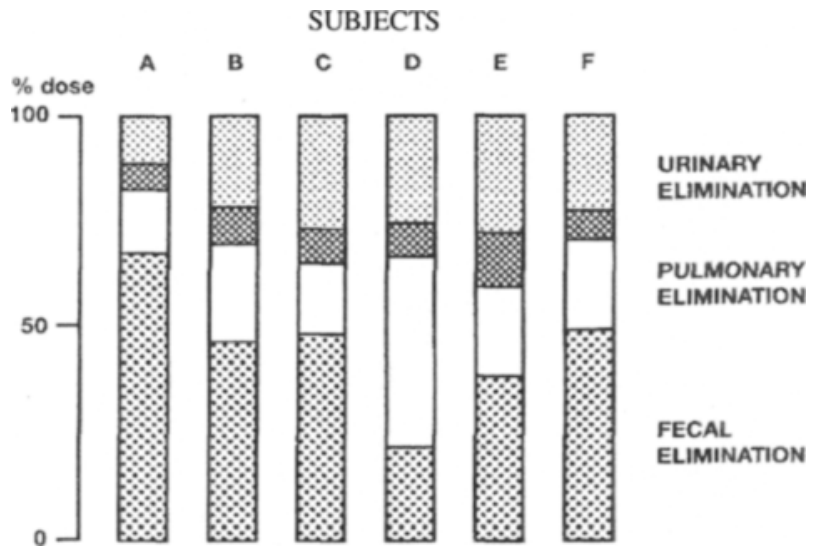

Figure 5. Comparison of urinary, faecal and pulmonary elimination of ${ }^{14} \mathrm{C}$ ENDOTFLON and its metabolites. Cumulated values over a period of 96 hours are expressed as \% eliminated as compared to the administered dose 
Table III. Balance sheet of urinary, faecal and pulmonary elimination over a 96-hours period of ENDOTELON and its metabolites in man after oral administration of the drug. Values are expressed as \% of he administered dose

\begin{tabular}{|c|c|c|c|c|c|c|c|}
\hline Route of elimination & \multicolumn{9}{|c|}{ \% of the administered dose } \\
\hline & A & B & C & D & E & F & $M \pm 2 \sigma$ \\
\hline Urinary & 10.96 & 21.31 & 26.31 & 25.20 & 27.27 & 21.48 & $22.09 \pm 5.99$ \\
Faecal & 67.54 & 46.24 & 48.27 & 21.69 & 39.91 & 50.03 & $45.61 \pm 14.92$ \\
Pulmonary & 6.26 & 8.99 & 7.69 & 8.29 & 13.24 & 7.43 & $8.65 \pm 2.43$ \\
\hline Total & 84.76 & 76.54 & 82.27 & 55.18 & 80.42 & 78.94 & $76.35 \pm 10.74$ \\
\hline
\end{tabular}

\section{Comparison of urinary, faecal and pulmonary elimination}

The cumulated individual values expressed as \% of the administered dose over 96 hours have been given in Table III.

The total elimination for the selected period of 96 hours was around $76 \%$ of the administered dose.

These results can be seen in Figure 4.

\section{DISCUSSION}

Considering the guidelines of the Medical Ethics Committee of the University Institution for experiments in man with radioactive tracer-labelled compounds, it was necessary to establish as precise as possible a balance between the amount of administered labelled compound and its elimination. Indeed, the Ethics Committee considers such a balance to be an extremely important factor, as it is a means of assessing the volunteers' exposure to ionizing irradiation.

As expected, plasma levels were relatively low considering the $150-\mathrm{mg}$ dose of ENDOTELON administered.

As regards the chemical structures of the administered products which constitute ENDOTELON, it is likely that they underwent a first-pass in the liver.

The values of urinary elimination varied from one subject to another but considering the results of faecal elimination, they can be compared, namely for almost all subjects with the exception of subject D whose faecal elimination was much lower than that of the others.

Concerning the rate of urinary elimination, it was observed that the greater part of the latter took place within 72 hours after drug administration. The quantities eliminated thereafter were very low. This is the reason why urine collection was no longer performed after 72 hours apart from subject $A$.
The faecal elimination was significant and amounted to $47 \%$ of the administered dose, essentially up to four days after drug administration. The interindividual variations observed, namely for the subject $\mathrm{A}$, must be considered in relation to his urinary elimination.

The quantities measured at faecal level must be partly attributed to elimination of the drug by biliary route, probably under the form of metabolites rather than to transit resulting from poor absorption.

Regarding the radioactivity measured at breath level, which must be attributed to the transformation of the ENDOTELON-labelled compound, although it was of significance, namely for determining the elimination balance analysis, it remained rather low.

Taking into account this last elimination route, the values of the balance sheet for the subject $A$ were high, i.e. about $76 \%$ over a 7 -days period after drug administration. Given this finding, it is possible that elimination via this route would continue to take place over the following days (Figure 4).

\section{Acknowledgements}

The authors thank Mr J. Necciari from SANOFI PHARMA (Clin Midy, Montpellier, France) for the control quality of tablets containing the labelled compounds as well for the HPLC quantification of procyanidolic oligomers (Figure 1).

\section{REFERENCES}

1. SANOFI PHARMA (1985): Projet d'Information Scientifique pour le compendium Suisse des médicaments: SANOFI PHARMA A.G., Basel, November 1985.

2. Massin M. (1981): Action de I'Endotélon sur les rétinopathies diabétiques. Gat. Med. France 89: 3272.

3. Delacroix P. (1981): Etude en double aveugle de I'Endotélon dans I'insuffisance veineuse chronique. Rev. Med. 22: 1793.

4. Glasson B., Benakis A. (1966): L'étude métabolique des médicaments marques: description d'un plan expérimental. J. Lab. Comp. 2: 210-218. 
5. Giasson B., Benakis A. (1971): The use of radioisotopes in drug metabolism. International Encyclopedia of Pharmacology and Therapeutics. Section 78, vol. 2, Pergamon Press.

6. Benakis A., Sugnaux F.R., Collet G.F., Kradolfer J.P., Berney C., Sion R., Necciari J., Cautreels W. (1986): Carbon 14 photosynthesis labelling of natural compounds and drugs from plants, In: Synthesis and Applications of Isotopically Labelled Compounds 1985, Elsevier Science Publishers B.V., Amsterdam, pp. 219-224.
7. Necciari J., Bourne M., Benakis A., Sion R., Cautreets W. (1986): HPLC analysis of ${ }^{14} \mathrm{C}$-labelled procyanidolic oligomers, extracted from grape seeds after a photosynthesis procedure under a ${ }^{14} \mathrm{CO}_{2}$ atmosphere. Journées Internationales d'Etude du Groupe Polyphénols. Montpellier, France, Juillet 1986

8. Benakis A. (1975): Appareil automatique de combustion de matériel biologique contenant du ${ }^{14} \mathrm{C}$ et du ${ }^{3} \mathrm{H}$. Brevet Français No 7331315, Kemtechnik 17,135. 